\title{
Evaluation of Anticoagulation Outcome among Patients Taking Warfarin: A Single-Center Experience, Northwest Ethiopia
}

\author{
Zelalem Liyew \\ University of Gondar \\ abilo tadesse ( $\square$ abilotad@gmail.com ) \\ University of Gondar \\ Nebiyu Bekele \\ University of Gondar \\ Tewodros Tsegaye \\ University of Gondar
}

\section{Research}

Keywords: Warfarin, INR, TTR, Northwest Ethiopia

Posted Date: January 6th, 2021

DOI: https://doi.org/10.21203/rs.3.rs-138820/v1

License: (c) (i) This work is licensed under a Creative Commons Attribution 4.0 International License. Read Full License 


\section{Abstract}

\section{Background}

Warfarin is a widely used oral anticoagulant in clinical practice. It is used to prevent arterial emboli in patients with atrial fibrillation, or prevent and treat venous thromboembolism. The efficacy and safety of warfarin depends on maintaining the INR within the therapeutic range. The proportion of time spent in the therapeutic INR range (TTR) is used to evaluate quality of anticoagulation control.

\section{Methods}

A hospital-based cross sectional study was conducted between November 1, 2019 and October 31, 2020 at Cardiac and Hematology Clinic, University of Gondar hospital. A consecutive sampling method was used to recruit 338 study subjects. Proportion of time spent in the therapeutic range (TTR) was calculated using the Rosendaal's linear interpolation method. TTR $\geq 65 \%$ was described as 'optimal' International Normalized Ratio (INR) control. The Data were entered into EPI Info version 4.4.1 and transported to SPSS version 20 for analysis. Logistic regression analysis was used to identify associated factors with optimal anticoagulation outcome (TTR $\geq 65 \%$ ). P-values $<0.05$ were used to declare significant association.

Result

A total of 338 study subjects were included in the study. The mean age of patients was 49 years. The majority of study participants attended formal education (79\%) and were urban dwellers (57\%). Atrial fibrillation was the commonest indication for warfarin therapy. One-third (33\%) of study subjects achieved the desired INRs (INR=2.0-3.0), while about one-tenth (13\%) of patients attained optimal INR control (TTR $\geq 65 \%$ ). There were no significant association of socio-demographic characteristics including age, gender, educational level and monthly income with optimal INR control (TTR $\geq 65 \%$ ). Likewise, clinical characteristics including dose of warfarin, warfarin adherence, frequency of INR determination, other concomitant drug intake, co-existing comorbidities, consumption of green leafy vegetables and alcohol intake didn't show significant association with optimal INR control (TTR $\geq 65 \%$ ).

Conclusion

Institution-based validated protocol might be required to overcome the poor TTR level. 'Anticoagulation (INR) clinic' would be required to 'scale-up' INR control.

\section{Background}

Warfarin is the widely prescribed oral anticoagulant in clinical practice. It is used to prevent arterial emboli in patients with atrial fibrillation, or prevent and treat venous thromboembolism (1-4). Warfarin has variable dose response and narrow therapeutic window, and thus requires frequent and regular international normalized ratio (INR) monitoring $(3,4)$. The proportion of time spent in the therapeutic INR 
range (TTR) is interpreted as the duration of time in which patient's INR values lie within the desired INR range (INR=2.0-3.0). It is used to evaluate quality of anticoagulation control. TTR $\geq 65 \%$ of the follow-up time is required to declare 'optimal' INR control. TTR $<65 \%$ increases the risk of thromboembolic or bleeding episodes $(5,7,11,13,14)$. Global studies documented that old age, obese individuals, dietary habits and other drugs intake, excessive alcohol consumption, renal or hepatic dysfunction were among the listed causes of poor INR control (TTR<65\%) $(8,9,11,13,19-24)$. The aim of the study is to determine the TTR and associated factors among patients taking warfarin in hospital setting, Northwest Ethiopia.

\section{Methods}

Study design and setting

A hospital-based cross sectional study was conducted between November 1, 2019 and October 31, 2020 at Cardiac and Hematology Clinic, University of Gondar hospital. The hospital is located in Northwest Ethiopia, which is $750 \mathrm{~km}$ away from the capital, Addis Ababa. The hospital had a catchment population of 5 million people.

Study subjects and variables

Study subjects

Patients older than 18 years old, and were on warfarin with follow up at Cardiac and Hematology Clinic, University of Gondar hospital were considered as study population.

Patients older than 18 years old, who were on warfarin for at least 6 months, had at least six INR determinations with each consecutive INR determination $\leq 56$ days apart were included in the study. Frequent records of INR at first month of drug initiation or during dose adjustments were excluded until stable INR values were obtained.

Study variables

Dependent variables: Proportion of time spent in the therapeutic INR range (TTR)

Independent variables: 1) Socio-demographic characteristics include age, gender, occupation, marital status, educational level, income level, residence and religion .2) Clinical characteristics include indication for warfarin, warfarin dosage, warfarin-plus drugs intake, adherence to warfarin, frequency of INR monitoring, co-existing comorbidities, nutritional status, alcohol intake and dietary habits.

Sample size and sampling procedure

The sample size was calculated using single population proportion formula with the assumption of $95 \%$ confidence level, $5 \%$ margin of error, and taking $30 \%$ for TTR in sub-Saharan African region. Consecutive sampling method was used to recruit 338 study subjects. 
Data collection instrument and procedures

Data were collected through an investigator administered pre-designed questionnaire. The questionnaire was prepared in English and translated into local language (Amharic) for data collection, and then retranslated back to English with maintaining its consistency. Patients were interviewed to obtain sociodemographic data. Relevant medical history and laboratory parameters were obtained from patients' records.

The proportion of INRs within the therapeutic range of 2.0-3.0 was calculated as number of INRs within the therapeutic range divided by the total number of INR measurements. TTR was calculated using Rosendaal's method, which used linear interpolation to assign an INR value to each day between successive observed INR values. The individual TTR determined the proportion of time spent in the therapeutic range of 2.0-3.0 for each patient. Those individuals with TTR $\geq 65 \%$ were declared to achieve 'optimal' INR control.

Data analysis

Data were entered into EPI Info version 4.4.1 and transported to SPSS version 20 for analysis.

Patient characteristics were reported as counts (percentages) for categorical variables, and mean with standard deviation for continuous variables. Bi-variable and multi-variable logistic regression models were constructed to identify independently associated factors with optimal INR control (TTR $\geq 65 \%$ ). Those variables with a P-value $<0.25$ in the bi-variate analysis were exported to multi-variate analysis to control the possible effect of confounders. Crude odds ratio (COR) and adjusted odds ratio (AOR) were reported. P-values $<0.05$ were used to declare significant association.

Ethical considerations

The research protocol complied with Declaration of Helsinki and was approved by local ethics committee. Study subjects were recruited only after informed written consent was obtained. All data obtained were treated confidentially. During the data collection process, those patients who were found to have atrial fibrillation and venous thromboembolism were taken care of as per the recommendations of AHA/ACC guideline and American Society of Hematology guideline respectively.

Definition of terms

TTR (proportion of time spent in the therapeutic range): The duration of time in which the patient's international normalized range (INR) values were within a desired range (INR $=2.0-3.0)$.

Chronic kidney disease: Abnormalities of kidney structure or function present for more than 3 months, with implications for health. Diagnosis of chronic kidney disease was settled by clinical, biochemical (raised serum creatinine) and/or imaging (ultrasound-proven reduced kidney size) findings. 
Chronic liver disease: Distorted liver architecture and decreased hepatic function as a result of chronic inflammation leading to chronic hepatitis or hepatic cirrhosis. Diagnosis was settled by ultrasoundevidenced liver surface irregularity and/or elevated serum transaminase $>3 x$ upper limit of normal.

Heart failure: Clinical syndrome that results from any structural or functional impairment of ventricular filling or ejection of blood. The Framingham criteria were used to diagnose heart failure.

Hyperthyroidism: Clinical state that involves excess synthesis and secretion of thyroid hormones by the thyroid gland. Diagnosis of hyperthyroidism was made in the presence of suggestive clinical symptoms and signs including enlarged thyroid gland, and confirmed by radioimmunoassay (RIA) test revealing low serum TSH and/or raised free T3/T4.

\section{Results}

Socio-demographic characteristics of study participants

A total of 338 patients taking warfarin, who had follow-up at Cardiac and Hematology Clinic, university of Gondar hospital were included in the study. The mean age of study subjects was 49 years. The majority of study participants were females (64\%), married (73\%) and urban dwellers (57\%). Most respondents were Christian by religion (86\%), and attended formal education (79\%) (Table-1).

Clinical characteristics of study participants

Three-quarters (75\%) of patients received warfarin for atrial fibrillation (Figure-1). More than half (59\%) of patients were taking warfarin $<5 \mathrm{mg}$ daily. Most patients (90\%) received other concomitant drugs like anti-hypertensive drugs, anti-platelets, lipid lowering drugs (statins), anti-thyroid drug (PTU) and antiretroviral drugs (ART). Most patients (84\%) got INR determination every month. Heart failure and hyperthyroidism was detected in $43 \%$ and $15 \%$ of patients respectively. One-third (36\%) of patients often consumed green leafy vegetables. Most (82\%) patients never had alcohol intake (Table-2).

Proportion of INRs and Time in Therapeutic Ranges

The mean proportion of INRs and TTR obtained from the study were shown in Figure-2 and 3. One-third (33\%) of study subjects achieved the proportion of INRs within the therapeutic range, while about onetenth $(13 \%)$ of patients attained optimal INR control (TTR $\geq 65 \%)$. A quarter $(25 \%)$ of patients on warfarin experienced bleeding episodes like epistaxis and vaginal bleeding, which required weekly INR determination and dose adjustment. Among those with bleeding episodes, $90 \%$ of patients had TTR $<65$ $\%$, and the remaining $10 \%$ had TTR $\geq 65 \%$.

Factors associated with TTR $<65 \%$ or $\geq 65 \%$

On bi-variable analysis, venous thromboembolism as indication for warfarin therapy was found to have significant association with TTR $\geq 65 \%$ (COR=0.135, 95\% Cl: 0.02-0.99, P-value $=0.049$ ), but not found to 
be significant on multivariable analysis. Multi-variable analysis didn't reveal significant association of socio-demographic characteristics including age, gender, educational level and monthly income with optimal INR control (TTR $\geq 65 \%$ ). By the same token, clinical characteristics including dose of warfarin, warfarin adherence, frequency of INR determination, other concomitant drug intake, co-existing comorbidities, consumption of green leafy vegetables and alcohol intake didn't show significant association with optimal INR control (TTR $\geq 65 \%)$ (Table-3).

\section{Discussion}

A total of 338 patients who were taking warfarin were included in the study. Atrial fibrillation (75\%) was the commonest indication for warfarin therapy. Atrial fibrillation, prosthetic heart valves, and venous thromboembolism were the shared indications for anticoagulation in sub-Saharan African settings (1417). Studies from United States and Europe had shown the proportions of desired INRs (INR=2.0-3.0) and TTR $\geq 65 \%$ were $50-70 \%$ and $40-60 \%$ respectively (7-11). Likewise, it was $40-50 \%$ and $30-40 \%$ respectively in Middle-Income countries (12,13). Sub-Saharan African studies indicated that $30-40 \%$ and $15-25 \%$ were reported magnitude of desired INRs and TTR $\geq 65 \%$ respectively (14-18). In this study, one-third of study subjects (33\%) achieved mean desired INRs, while about one-tenth (13\%) of patients attained TTR $\geq 65 \%$. The finding in this study showed 'poor' anticoagulation outcome, congruent with reports from other subSaharan African countries. Half of the patients attained sub-therapeutic INR range $(I N R<2.0)$ and were taking warfarin $<5 \mathrm{mg}$ daily, which might explain physicians' less comfort on up-titration of warfarin dose. Lack of an institution validated protocol for warfarin dosage titration might contribute to poor INR outcome. A quarter (25\%) of patients experienced bleeding episodes. Most $(90 \%)$ bleeding episodes occurred among those who had poor INR control. African studies reported that $14-17 \%$ of patients bled while on warfarin therapy $(15,20)$. Western literatures documented 'optimal' INR control prevents bleeding episodes and thrombotic events $(2,4,5,7,10)$. Bi-variable analysis showed 'indication of warfarin' for venous thromboembolism was significantly associated with good INR control, which might be explained by appropriate adherence to warfarin among those who required warfarin for limited period. There were no significant association of socio-demographic characteristics including age, gender, educational level and monthly income with optimal INR outcome (TTR $\geq 65 \%)$. Likewise, clinical characteristics including dose of warfarin, warfarin adherence, frequency of INR determination, other concomitant drug intake, coexisting comorbidities, consumption of green leafy vegetables and alcohol intake didn't show significant association with optimal INR control. Global studies documented that old age, obese individuals, other concomitant drug intake, excessive alcohol intake, renal or hepatic dysfunction were among listed causes of poor INR control (TTR<65\%) (8-13,19-24). Novel oral anticoagulants (NOACs) are recently introduced anticoagulants, which have a number of advantages over warfarin, despite limited access, cost issue and availability of antidote. NOACs are prescribed in fixed doses, have fewer interactions with food and drugs, and do not require routine anticoagulant monitoring. Their use might be considered for eligible patients with atrial fibrillation and venous thromboembolism $(9,11-13,16,18)$.

Limitation of the study 
Selection bias couldn't be avoided as consecutive sampling method was used to recruit study subjects.

\section{Conclusion}

One-third (33\%) of patients taking warfarin achieved therapeutic INR range (INR=2.0-3.0). Majority (87\%) of patients had poor INR control (TTR<65\%). One-fourth ( $25 \%$ ) of patients experienced adverse bleeding episodes.

Recommendation

The authors recommend large scale prospective study to determine risk factors for poor INR control (TTR $<65 \%$ ) in Ethiopia. Institution-based validated protocol might be required to overcome the poor TTR level. 'Anticoagulation (INR) clinic' would be required to 'scale-up' INR control.

\section{Declarations}

\section{Acknowledgements}

We are grateful to thank the study participants and their health personnel.

\section{Authors' contributions}

ZL contributed to the conception, design, data collection, analysis, writing, and review of the manuscript. AT contributed to the conception, design, analysis, writing and review of the manuscript. NB and TT contributed to conception, design, analysis and review of the manuscript. All authors read and approved the final manuscript and approved its submission for publication.

\section{Funding}

Funding for research was obtained from 'Research and Publication Office' of College of Medicine and Health Sciences, University of Gondar. The funding body had no role in the design of the study, data collection, analysis and interpretation of the data.

\section{Availability of data and materials}

All data generated and analyzed are included in this research article.

\section{Ethics approval and consent to participate}

Ethical approval was obtained from the Institutional Review Board of College of Medicine and Health Sciences, University of Gondar. Formal letter of permission was obtained from University of Gondar hospital administrative body. Study subjects were recruited only after informed written consent was obtained. 


\section{Consent for publication}

NA

\section{Competing interests}

The authors declare that they have no competing interests.

\section{References}

1. January CT, Wann LS, Alpert JS, Calkins H, Cigarroa JE, Conti JB, et al. 2014 AHA/ACC/HRS guideline for the management of patients with atrial fibrillation: A report of the American College of Cardiology/American Heart Association task force on practice guidelines and the Heart Rhythm Society. J Am Coll Cardiol. 2014;64(21):2246-80.

2. American society of hematology 2020 guidelines for management of venous thromboembolism: treatment of deep vein thrombosis and pulmonary embolism. Blood Adv 2020;4(99):4693-4738.

3. Hirsh J, Fuster V, Ansell J, Halperin JL. American Heart Association/American College of Cardiology foundation guide to warfarin therapy. Circulation 2003;107:1692-1711.

4. Hirsh J, Dalen JE, Anderson DR, Poller L, Bussey H, Ansell J, et al. Oral anticoagulants: Mechanisms of action, clinical effectiveness, and optimal therapeutic range. Chest 2001;119:8S-21S.

5. Rivera-Caravaca JM, Roldan V, Esteve-Pastor MA, Valdes M, Vicente V, Lip GVH, et al. Importance of time in therapeutic range on bleeding risk prediction using clinical risk scores in patients with atrial fibrillation. Sci Reports 2017;7:12066. https://doi:10.1038/S41598-017-11683-2.

6. Erkens PM, Cate HT, Buller HR, Prins MH. Benchmark for time in therapeutic range in venous thromboembolism. A systematic review and meta-analysis. Plos One.2012:7(9):e42269

7. Singer DE, Hellkamp AS, Piccini JP, Mahaffey KW, Cokhnyginay Y, Pan G, et al. Impact of global geographic region on time in therapeutic range on warfarin anticoagulant therapy: Data from the Rocket AF clinical trial. J Am Heart Assoc 2013;2:e000067.

8. Rose AJ, Ozonoff A, Henault LE, Hylek EM. Warfarin for atrial fibrillation in community-based practice. Journ Thromb Hemos 2008:6:1647-54.

9. Macedo AF, Bell J, Mc Carron C, Conroy R, Richardson J, Scowcroft A, et al. Determinants of oral anticoagulation control in new warfarin patients: analysis using data from clinical practice research data link. Thromb Res 2015;136:250-60.

10. Barrios V, Escobar C, Prieto L, Osorio G, Polo J, Lobos JM, et al. Anticoagulation control in patients with non valvular atrial fibrillation attended at primary care centers in Spain: The PAULA study. Rev Esp Cardiol 2015;68(9):769-76.

11. Caldeira D, Cruz I, Morgado G, Stuart B, Gomes C, Martins C, et al. Evaluation of time in therapeutic range in anticoagulated patients: a single-center, retrospective, observational study. BMC Res Notes. 2014;7:891-95. 
12. Silva PGMB, Sznejder H, Vasconcellos R, Charles GM, Mendonca-Filho HTF, Mardekian J, et al. Quality of anticoagulation management in warfarin treated patients with non-valvular atrial fibrillation: A descriptive real-world study in a private setting in Brazil. J Am Coll Cardiol 2018;71(11):A376.

13. Hong K-S, Kim Y-K, Bae h-j, nam HS, Kwon SU, Bang OY, et al. Quality of anticoagulation with warfarin in Korean patients with atrial fibrillation and prior stroke. A multicenter retrospective observational study. J Clin Neurol 2017;13(3):273-80.

14. Mwita JC, Francis JM, Oyekunle AA, Gaenamong M, Goepamang M, Magafu MGMO. Quality of anticoagulation with warfarin at a tertiary hospital in Botswana. Clin Applied Throm/Hemos. 2018;24(4):591-601.

15. Sonuga BO, Hellenberg DA, Cupido CS, Jaeger C. Profile and anticoagulation outcomes of patients on warfarin therapy in an urban hospital in Cape Town, South Africa. Afr J Prm Health Care Family Med 2016;8(1):a1032.

16. Ebrahim I, Bryer A, Cohen K, Mouton JP, Msemburi W, Blockman M. Poor anticoagulation control in patients taking warfarin at a tertiary and district level prothrombin clinic in Cape Town, South Africa. S Afr Med Jour. 2018;108(6):490-94.

17. Fenta TG, Assefa T, Alemayehu B. Quality of anticoagulation management with warfarin among outpatients in a tertiary hospital in Addis Ababa, Ethiopia: a retrospective cross-sectional study. BMC Health Serv Res. 2017;17(1):389-96.

18. Endewunet E, Tadesse A, Adane A, Abdulkadir M. Appropriate use of anti-thrombotic therapy in patients with atrial fibrillation at single-center experience, Northwest Ethiopia. BMC Cardiovasc Dis 2020;20:375-84.

19. Roth JA, Bradley K, Thummel KE, Veenstra DL, Boudreau D. Alcohol misuse, genetics, and major bleeding among warfarin therapy patients in a community setting. Pharmacoepidemiol Drug Saf 2015;24(6):619-27.

20. Teklay G, Shiferaw N, Legesse B, Bekele ML. Drug-drug interactions and risk of bleeding among inpatients on warfarin therapy. A prospective observational study. Thrombosis Journal 2014;12:2028.

21. Limdi NA, Nolin TD, Booth SL, Centi A, Marques MB, Crowley MR, et al. Influence of kidney function on risk of supratherapeutic international normalized ratio-related hemorrhage in warfarin users. $A$ prospective cohort study. Am J Kidney Dis 2015;65(5):701-09.

22. Qamar A, Vaduganathan M, Greenberger NJ, Giugliano RP. Oral anticoagulation in patients with liver disease. J Am College Cardiol 2018:71(19):2162-75.

23. Hart RH, Veenstra DL, Boudreau DM, Roth JA. Impact of body mass index and genetics on warfarin major bleeding outcomes in a community setting. Am J Med 2017;130:222-28.

24. Khan TI, Kamali F, Kesteven P, Avery P, Wynne H. The value of education and self- monitoring in the management of warfarin therapy in older patients with unstable control of anticoagulation. $\mathrm{Br} \mathrm{J}$ Haematol 2009;126:557-64. 


\section{Tables}

Table 1: Socio-demographic characteristics of patients taking warfarin in University of Gondar hospital, Northwest Ethiopia, November 1, 2019 to October 31, 2020 ( $n=338)$

\begin{tabular}{|c|c|c|}
\hline Variables & Frequency (No.) & Percentage (\%) \\
\hline \multicolumn{3}{|l|}{ Age (years) } \\
\hline$<40$ Years & 115 & 34.0 \\
\hline $40-60$ years & 110 & 32.5 \\
\hline$>60$ Years & 113 & 33.5 \\
\hline \multicolumn{3}{|l|}{ Gender } \\
\hline Male & 121 & 35.8 \\
\hline Female & 217 & 64.2 \\
\hline \multicolumn{3}{|l|}{ Residence } \\
\hline Urban & 193 & 57.1 \\
\hline Rural & 145 & 42.9 \\
\hline \multicolumn{3}{|l|}{ Religion } \\
\hline Christian & 290 & 85.8 \\
\hline Muslim & 48 & 14.2 \\
\hline \multicolumn{3}{|l|}{ Marital status } \\
\hline Single & 61 & 18.0 \\
\hline Married & 247 & 73.1 \\
\hline Others & 30 & 8.9 \\
\hline \multicolumn{3}{|l|}{ Educational level } \\
\hline Can't read and write & 71 & 21.0 \\
\hline Can read and write & 103 & 30.5 \\
\hline Elementary school & 51 & 15.1 \\
\hline Secondary school & 64 & 18.9 \\
\hline College and above & 49 & 14.5 \\
\hline \multicolumn{3}{|l|}{ Occupation } \\
\hline Government employee & 39 & 11.5 \\
\hline Merchant & 61 & 18.0 \\
\hline House wife & 127 & 37.6 \\
\hline Farmer & 73 & 21.6 \\
\hline Student & 38 & 11.3 \\
\hline \multicolumn{3}{|l|}{ Monthly income (in Birr) } \\
\hline$<1500$ & 183 & 54.1 \\
\hline $1500-3000$ & 85 & 25.1 \\
\hline$>3000$ & 70 & 20.8 \\
\hline
\end{tabular}

Table 2: Clinical characteristics of patients taking warfarin in University of Gondar hospital, Northwest Ethiopia, November 1, 2019 to October 31, $2020(n=338)$ 


\begin{tabular}{|c|c|c|}
\hline Clinical characteristics & Frequency (No.) & Percentage (\%) \\
\hline \multicolumn{3}{|l|}{$\operatorname{BMI}\left(\mathrm{kg} / \mathrm{M}^{2}\right)$} \\
\hline$<18.5$ & 29 & 8.6 \\
\hline $18.5-24.9$ & 229 & 67.8 \\
\hline$\geq 25.0$ & 80 & 23.6 \\
\hline \multicolumn{3}{|l|}{ Indication for warfarin } \\
\hline Atrial fibrillation & 252 & 74.6 \\
\hline Venous thromboembolism & 72 & 21.3 \\
\hline Others & 14 & 4.1 \\
\hline \multicolumn{3}{|l|}{ Dose of warfarin } \\
\hline$<5 \mathrm{mg}$, daily & 199 & 58.9 \\
\hline $5 \mathrm{mg}$, daily & 118 & 34.9 \\
\hline$>5 \mathrm{mg}$, daily & 21 & 6.2 \\
\hline \multicolumn{3}{|l|}{ Ever missed warfarin dose } \\
\hline Yes & 42 & 12.4 \\
\hline No & 296 & 87.6 \\
\hline \multicolumn{3}{|l|}{ Warfarin-plus drugs use } \\
\hline Yes & 305 & 90.2 \\
\hline No & 33 & 9.8 \\
\hline \multicolumn{3}{|l|}{ Frequency of INR monitoring } \\
\hline Every 2 weeks & 32 & 9.5 \\
\hline Every 1 month & 283 & 83.7 \\
\hline Every 2 months & 23 & 6.8 \\
\hline \multicolumn{3}{|l|}{ Alcohol intake } \\
\hline Yes & 61 & 18.0 \\
\hline No & 277 & 82.0 \\
\hline \multicolumn{3}{|l|}{ Often use leafy vegetables } \\
\hline Yes & 122 & 36.1 \\
\hline No & 216 & 63.9 \\
\hline \multicolumn{3}{|l|}{ LFT (serum ALT) } \\
\hline Normal ALT & 138 & 40.8 \\
\hline Raised ALT & 17 & 5.0 \\
\hline Unknown & 183 & 54.2 \\
\hline \multicolumn{3}{|l|}{ RFT (serum Cr) } \\
\hline Normal $\mathrm{Cr}$ & 212 & 62.7 \\
\hline Raised $\mathrm{Cr}$ & 29 & 8.6 \\
\hline Unknown & 97 & 28.7 \\
\hline \multicolumn{3}{|l|}{ Heart failure } \\
\hline Yes & 144 & 42.6 \\
\hline No & 194 & 57.4 \\
\hline \multicolumn{3}{|l|}{ Hyperthyroidism } \\
\hline Yes & 46 & 13.6 \\
\hline No & 292 & 86.4 \\
\hline
\end{tabular}

NB:, ALT, alanine aminotransferase; BMI, body mass index, $\mathrm{Cr}$, creatinine; GFR, glomerular filtration rate; LFT, liver function test; RFT, renal function test

Table 3: Bivariate and multivariate regression analysis of time in therapeutic INR range (TTR) among patients taking warfarin in University of Gondar, Northwest Ethiopia, November 1, 2019 to October 31, $2020(n=338)$ 


\begin{tabular}{|c|c|c|c|c|c|}
\hline Variables & \multicolumn{2}{|c|}{ TTR } & $\mathrm{COR}(\mathrm{Cl})$ & $\mathrm{AOR}(\mathrm{CI})$ & P-value \\
\hline \multicolumn{6}{|l|}{ Age } \\
\hline$<40$ ycars & 100 & 15 & $1.04(0.48,2.27)$ & $0.45(0.13,1.59)$ & 0.214 \\
\hline 40-60 years & 97 & 13 & $0.94(0.42,2.12)$ & $0.73(0.28,1.90)$ & 0.515 \\
\hline$>60$ ycars & 99 & 14 & 1 & & \\
\hline \multicolumn{6}{|l|}{ Gender } \\
\hline Male & 103 & 18 & 1 & & \\
\hline Female & 193 & 24 & $1.41(0.73,2.71)$ & $1.23(0.55,2.76)$ & 0.617 \\
\hline \multicolumn{6}{|l|}{ Marital status } \\
\hline Single & 50 & 11 & 1 & & \\
\hline Married & 218 & 28 & $1.98(0.51 .7 .71)$ & $1.77(0.24 .13 .29)$ & 0.579 \\
\hline Others & 27 & 3 & $1.15(0.33,4.04)$ & $1.70(0.44,6.58)$ & 0.442 \\
\hline \multicolumn{6}{|l|}{ Montihly income } \\
\hline$<1500$ birr & 157 & 26 & 1 & & \\
\hline $1500-3000$ birr & 77 & 8 & $1.28(0.55 .2 .99)$ & & \\
\hline$>3000 \mathrm{birr}$ & 62 & 8 & $0.81(0.29 ; 2.27)$ & & \\
\hline \multicolumn{6}{|l|}{ Educational level } \\
\hline $\mathrm{Can}^{2} \mathrm{t}$ read and write & 61 & 10 & 1 & & \\
\hline Can read and write & 91 & 12 & $1.80(0.53,6.12)$ & & \\
\hline Elementary school & 45 & 6 & $1.45(0.44,4.76)$ & & \\
\hline Secondary school & 54 & 10 & $1.47(0.39,5.56)$ & & \\
\hline College and above & 44 & 4 & $2.04(0.60,6.94)$ & & \\
\hline \multicolumn{6}{|l|}{ Residence } \\
\hline Urban & 170 & 23 & $0.89(0.47,1.72)$ & & \\
\hline Rural & 126 & 19 & 1 & & \\
\hline \multicolumn{6}{|l|}{$\operatorname{BMI}\left(\mathrm{kg} \mathrm{M}^{2}\right)$} \\
\hline$<18.5$ & 25 & 4 & 1 & & \\
\hline $18.5-24.9$ & 199 & 30 & $1.44(0.39,5.19)$ & & \\
\hline$\geq 25$ & 72 & 8 & $1.36(0.59,3.09)$ & & \\
\hline \multicolumn{6}{|l|}{ Indication for warfarin } \\
\hline Atrial fibrillation & 222 & 30 & 1 & & \\
\hline VTE & 64 & 8 & $0.14(0.02,0.99)$ & $0.49(0.11,2.14)$ & 0.341 \\
\hline Others & 10 & 4 & $0.31(0.08,1.23)$ & $0.48(0.09,2.51)$ & 0.386 \\
\hline \multicolumn{6}{|l|}{ Dose of warfarin } \\
\hline$<$ smg daily & 181 & 18 & 1 & & \\
\hline $5 \mathrm{mg}$ daily & 98 & 20 & $0.39(0.12,1.32)$ & $0.40(0.09,1.64)$ & 0.206 \\
\hline$>5 \mathrm{mg}$ daily & 17 & 4 & $0.91(0.28,2.98)$ & $0.94(0.24,3.74)$ & 0.930 \\
\hline \multicolumn{6}{|c|}{ Ever missed VKA dose } \\
\hline Yes & 40 & 2 & 1 & & \\
\hline No & 266 & 30 & $2.26(0.52,9.81)$ & $1.9(0.99,9.21)$ & 0.426 \\
\hline \multicolumn{6}{|l|}{ VKA-plus drugs use } \\
\hline Yes & 268 & 37 & 1 & & \\
\hline No & 28 & 5 & $1,29(0.47,3.56)$ & & \\
\hline Frequency of INR mo & onitoring & & & & \\
\hline Every 2 wecks & 28 & 4 & $0.68(0.15,3.05)$ & & \\
\hline Every 1 month & 249 & 34 & $0.68(0.15 .3 .05)$ & & \\
\hline Every 2 months & 19 & 4 & 1 & & \\
\hline Alcohol intake & & & & & \\
\hline Yes & 54 & 6 & 1 & & \\
\hline No & 241 & 36 & $1.34(0.54 .3 .34)$ & & \\
\hline Often use leafy veget & tables $\cong$ & ekly) & & & \\
\hline Yes & 105 & 17 & 1 & & \\
\hline No & 191 & 25 & $0.80(0.41,1.56)$ & & \\
\hline Liver function tests & & & & & \\
\hline Normal & 122 & 16 & 1 & & \\
\hline Abnormal & 14 & 3 & $0.91(0.46,1.80)$ & & \\
\hline Unknown & 160 & 23 & $1.49(0.39,5.59)$ & & \\
\hline Renal function test $(C)$ & (GFR) & & & & \\
\hline Normal & 184 & 28 & 1 & & \\
\hline Reduced & 25 & 4 & $1.32(0.62,2.85)$ & & \\
\hline Unknown & 87 & 10 & $1.39(0.40,4.82)$ & & \\
\hline Heart failure & & & & & \\
\hline Yes & 130 & 14 & 1 & & \\
\hline No & 166 & 28 & $0.64(0.32,1.26)$ & $1.59(0.69,3.68)$ & 0.276 \\
\hline Hyperthyroodism & & & & & \\
\hline Yes & 45 & 6 & 1 & & \\
\hline No & 251 & 36 & $0.93(0.37,2.33)$ & & \\
\hline
\end{tabular}

NB: BMI, body mass index; VKA, vitamin K antagonist; VTE, venous thromboembolism

Figures 


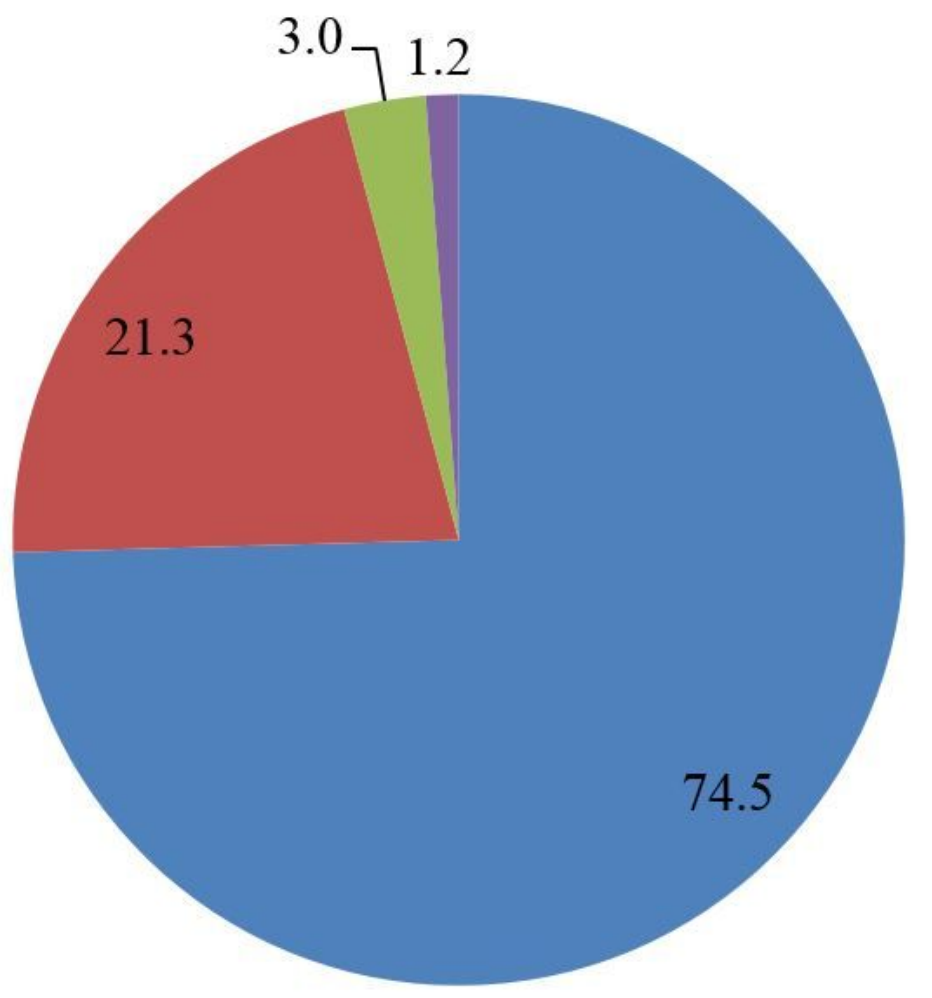

$\square \mathrm{AF}$

- VTE

- Intracardiac Thrombus

- Prosthetic valve

\section{Figure 1}

Pie chart for indication of warfarin therapy. NB: AF, atrial fibrillation; VTE, venous thromboembolism; 


\section{Proportion of INR ranges}

Supratherapeutic INR range (INR>3)

Therapeutic INR range (INR=2-3)

Sub-therapeutic INR range (INR<2)
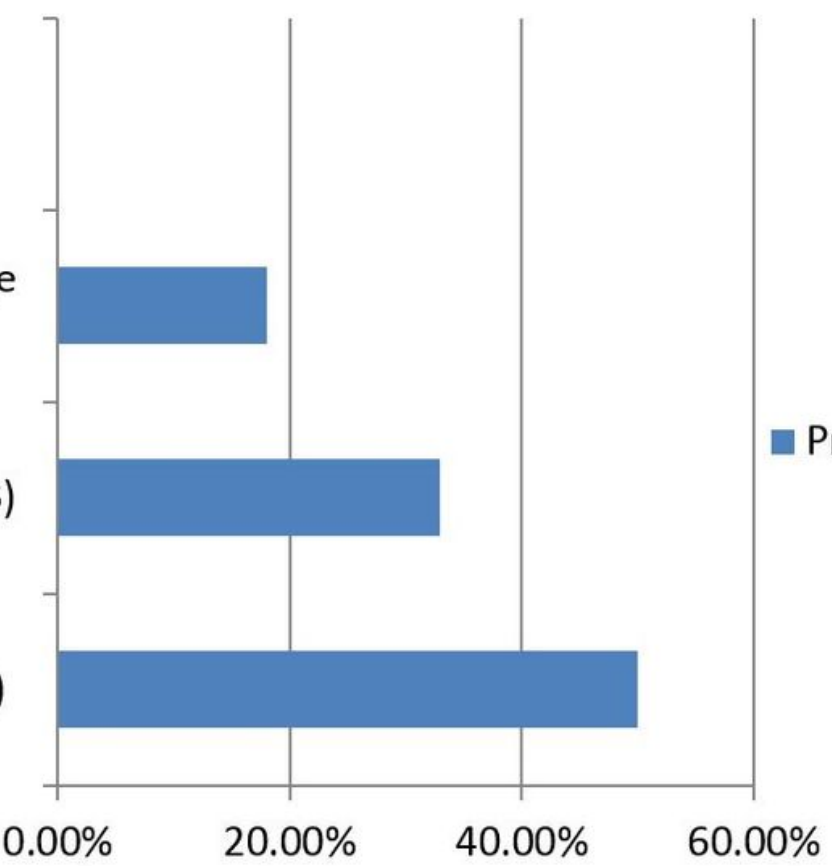

Proportion of INR ranges

\section{Figure 2}

Bar diagram for proportion of INR range

\section{Proportion of TTR (\%)}

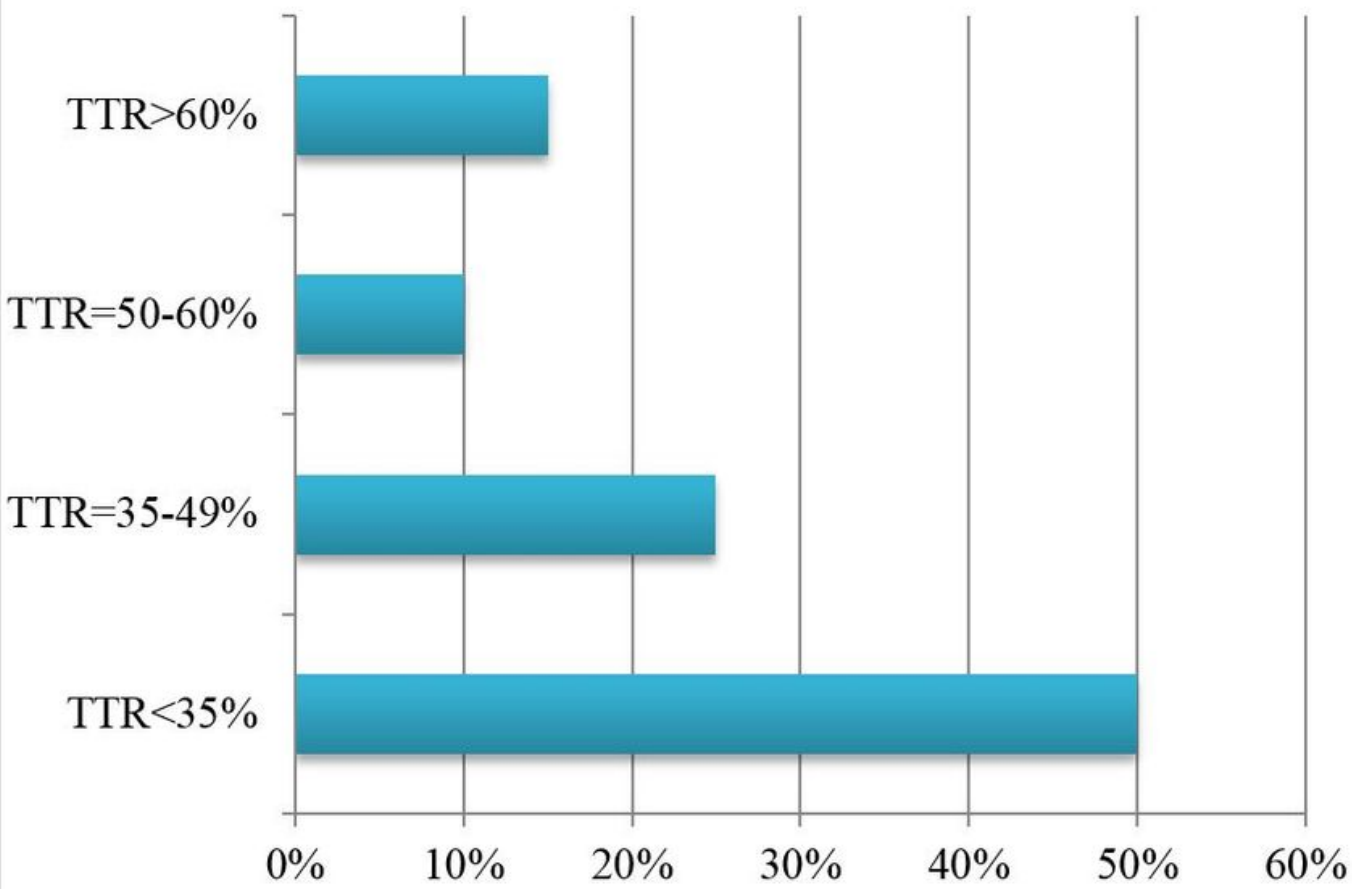

- Proportion of TTR (\%) 
Figure 3

Bar diagram for proportion of time in therapeutic INR range 